\title{
Restauro contemporâneo: algumas abordagens (1)
}

Alessandro Pergoli Campanelli*

\section{Resumo}

O texto visa apresentar a diversidade de abordagens contemporâneas de restauro, a partir de dois casos específicos. No caso da enorme área arqueológica de Angkor, no Camboja, que está listada como parte do Patrimônio Mundial da UNESCO, são apresentadas as diversas intervenções levadas a cabo pelas várias equipes de restauração, de nacionalidades diferentes, nos vários templos do grande complexo. Discutem-se também questões conceituais decorrentes da invasão das ruínas pela vegetação tropical. No caso dos Amorini de Canova, são apresentadas as circunstâncias que levaram aos diferentes estados de conservação das esculturas, o que nos leva a refletir sobre as implicações das diversas formas de tratamento das superfícies externas das obras arquitetônicas. De ambos os casos relatados, extraem-se elementos para uma reflexão crítica sobre as diferentes orientações teóricas da disciplina do restauro e da conservação na Europa.

Palavras-chave: Restauração. Preservação do patrimônio. Patrimônio cultural.

\section{Contemporary restoration: some approaches}

\begin{abstract}
The article intends to present different contemporary approaches to restoration, from two specific case studies. The varied interventions performed by the multiple intervention teams, of different nationalities, in the many temples of the great archeological complex of Angkor, in Cambodia - listed as World Monument by UNESCO - are presented. Conceptual issues derived from the invasion of the ruins by the luxurious tropical vegetation are also discussed. In the case of Canova's Amorini, the different circumstances which led to the different conservation status of the sculptures are presented, leading us to consider the implications of the different forms of treatment of the external finishes of architectural assets. From both cases, elements for a critical evaluation of the different theoretical orientations of the field of restoration and conservation in Europe emerge.
\end{abstract}

Key-words: Restoration. Preservation of cultural heritage. Cultural heritage. 


\section{Restauros em Angkor (Camboja): algumas questões em aberto}

O grande parque de Angkor, situado no coração da floresta cambojana, com uma extensão de mais de $200 \mathrm{~km}^{2}$, é provavelmente a maior área arqueológica do mundo.

Atualmente, muitos projetos internacionais se voltam ao restauro e à conservação de seus fascinantes templos. A história das restaurações modernas é, no entanto, relativamente recente e remonta às primeiras décadas do século passado. As majestosas ruínas da antiga cidade de Angkor foram, com efeito, apresentadas ao mundo ocidental apenas em junho de 1860 quando uma expedição de naturalistas franceses, comandada por Henri Mouhot e financiada pela Royal Geographical Society de Londres, dirigiu-se ao interior da densa floresta tropical do norte do Camboja e passou três semanas estudando os remanescentes de uma imensa área arqueológica completamente envolvida pela vegetação. Em realidade, muitos outros exploradores, provenientes da China, do Japão, da Arábia, da Espanha e de Portugal, já a partir do século XVI, haviam percorrido a estrada que, da atual capital do Camboja, Phnom Penh, levava à Bangkok, atravessando uma floresta tropical, descrita como sendo uma das mais selvagens entre as conhecidas, e deixaram numerosos testemunhos do estupor experimentado ao se depararem com imponentes construções envolvidas em mistério (2).

A área arqueológica de Angkor possui, em seu interior, centenas de templos e santuários representativos das várias fases do antigo império Khmer. Cada um deles segue, em sua constituição, rígidos esquemas geométricos (hoje reconhecíveis por suas imensas dimensões através das fotos de satélites) com poucas variantes. Ao redor deles, um sistema de canais, rigorosamente geométrico e engenhoso, alimentava gigantescas bacias hidrográficas (as baray) e servia para irrigar os arrozais durante a estação seca e também como principal via de transporte e de drenagem da água durante o período das chuvas, e, ainda, como rede de distribuição hídrica.

Particularmente relevante pela extensão e riqueza do aparato decorativo são a "sagrada" Angkor Wat (em sânscrito, "cidade-templo" erigida durante o apogeu do império Khmer, sob Suryavarman II, no século XII) que, recobrindo uma área de mais de 80 hectares, é provavelmente o maior edifício religioso do mundo, e a gigantesca Angkor Thom ("cidade grande"), fundada no final do século XII por Jayavarman VII. 
Para entender como foi possível "esquecer" por tantos séculos um complexo tão grandioso é necessária uma breve digressão histórica: o império Khmer teve de se defender do reino Thai, a oeste, e do Chặm, a leste. No início do século XV (em torno de 1432) o rei Ponhea Yat, derrotado pelos Thai, refugiou-se com sua corte em Phnom Penh, à espera da enésima desforra. Angkor, por longo tempo saqueada, arruinou-se. As casas e os templos abandonados foram rapidamente envolvidos pela vegetação, caindo, ao mesmo tempo, no esquecimento. Nem todos os edifícios tiveram a mesma sorte: o mais importante deles, o templo de Angkor Wat, mesmo se antes danificado pelas tropas do Sião, e depois, muito provavelmente, pela população local em busca de materiais de construção, não foi jamais abandonado de todo. No século XVI, readquiriu funcionalidade com os reis Ang Chan e Satha que ali realizaram uma série de completamentos e restauros como testemunhado por algumas antigas inscrições presentes nas colunas do templo de Angkor Wat.

Estudos recentes permitiram documentar como, durante o reinado de Ang Chan, foi restaurada e completada a decoração das grandes galerias internas (as do quadrante noroeste), que representam cenas complexas da mitologia hinduísta. Esses dados são de grande interesse pois demonstram como já em tempos antigos eram feitas em Angkor operações de restauro (e talvez também de conservação). Sucessivamente, os monges budistas, que ocuparam o templo a partir do século XVII, realizaram limitadas, mas constantes, manutenções, e permitiram que Angkor Wat se conservasse quase íntegro em suas partes principais, diferentemente de muitos outros edifícios que não receberam nenhum cuidado.

O grandioso império Khmer, nos quatrocentos anos sucessivos, ficou, alternadamente, sob a tutela tailandesa ou vietnamita até que, em 1864, o rei Norodom aceitou o protetorado da França e o Camboja foi incorporado na nascente Union indochinoise junto ao Laos e ao atual Vietnam (3). Um papel fundamental no conhecimento e no estudo da civilização de Angkor teve a École Française de l'Extrême-Orient (EFEO Escola Francesa do Extremo-Oriente) (4) que em 1907 fundou o escritório para a "Conservation du site monumental d'Angkor" [Conservação do Sítio Monumental de Angkor]. Desde então o grande parque arqueológico, aberto ao público oficialmente em 1925, teve seus templos paulatinamente liberados da vegetação, estudados e parcialmente restaurados por diversas gerações de estudiosos, arqueólogos e arquitetos, até 1972 quando, com o início dos conflitos e a instauração sucessiva da 
ditadura brutal do Khmer Vermelho (1975-1979), o Instituto foi obrigado a deixar o Camboja. Naqueles anos, todas as missões estrangeiras presentes no local tiveram de deixar o país, e os próprios especialistas cambojanos trabalharam em condições precárias, até ser literalmente obrigados a interromper as restaurações em curso.

No entanto, o sanguinolento regime de Pol Pot mostrou-se bastante respeitoso em relação aos antigos vestígios Khmer (5), utilizados como símbolo de uma mítica idade de ouro à qual podiam aludir com orgulho nacionalista.

Os piores danos para os monumentos verificaram-se depois de 1979 quando, ao perder o controle oficial do país, o Khmer Vermelho iniciou uma luta armada nos campos que acabaria somente quinze anos mais tarde. Os templos de Angkor, que se tornaram palco de uma longa guerrilha, foram, com efeito, utilizados como refúgio pelos guerrilheiros (em particular Angkor Wat) e toda a área foi minada. Foi nesse período que, aproveitando do clima de incerteza política, foram feitos os grandes saques, em especial nos templos submersos na floresta e menos freqüentados (6).

Somente em 1992 foram retomadas as operações para a tutela do sítio, com a inscrição de Angkor na Lista do Patrimônio Mundial da UNESCO e as conseqüentes medidas para a salvaguarda dos monumentos adotadas pelo novo governo cambojano. Entre elas, a mais importante é o estabelecimento de uma espécie de zoneamento, presente no Decreto Real Estabelecendo Zonas Culturais Protegidas, que prevê, para toda a região de Siem Reap/Angkor, uma série de medidas de proteção, gradativamente mais branda quanto mais distante do parque monumental. (7) A tutela e a administração de todo o parque são atribuídas à Authority for the Protection and Management of Angkor [Autoridade para a Proteção e Administração de Angkor], uma organização especial instituída em 1995, conhecida como APSARA, nome khmer das divindades femininas representadas nos baixo-relevos dos templos. De importância fundamental é ainda o ICC (International Coordinating Committee for the Safeguarding and Development of the Historic Site of Angkor - Comitê Internacional de Coordenação para a Salvaguarda e Desenvolvimento do Sítio Histórico de Angkor) que se reúne duas vezes por ano para monitorar os projetos em execução e aprovar as novas iniciativas para toda a área (8).

Para quem está habituado com as refinadas instituições para a tutela dos bens culturais existentes na Itália há mais de um século, essas estruturas podem parecer banais e 
seus instrumentos rudimentares; no entanto, mesmo sem mencionar o caos institucional gerado pelos horrores do conflito, em que mais de $25 \%$ da população cambojana perdeu violentamente a vida, é necessário levar em conta sobretudo a extrema variedade (e, muitas vezes, a incoerência) do sistema de tutela no panorama internacional. Também na Europa coexistem diversas abordagens, distantes entre si do ponto de vista operacional e nem sempre respeitosas das principais doutrinas codificadas em âmbito internacional (Carta de Restauro de Atenas, Carta de Veneza, Declaração de Amsterdã, Convenção Européia para a proteção do patrimônio arqueológico etc.).

Não é de surpreender, portanto, que essas diferenças sejam visíveis também numa área como a de Angkor, na qual atuam dezenas de instituições internacionais. Uma simples análise da terminologia utilizada para descrever as intervenções (conservation em vez de restoration, ou mesmo reconstruction, para nos atermos apenas à língua inglesa) poderia ser extremamente esclarecedora para compreender a enorme distância entre as diversas posturas. E esse é um atrativo ulterior para quem se ocupa da preservação, pois aos incríveis vestígios arquitetônicos, o parque monumental de Angkor associa também um panorama completo das restaurações efetuadas por quase todas as principais escolas internacionais (9) que ali atuaram e continuam a atuar, por vezes de modo semelhante, por vezes em total desacordo, criando, assim, além de qualquer juízo que se possa ter, uma interessantíssima seqüência de teorias e técnicas de intervenção. Deixando de lado os templos mais afastados do percurso principal, que ainda não passaram por intervenções, é possível encontrar seja monumentos parcialmente liberados da vegetação e mantidos de maneira cenográfica desmoronados, como Preah Khan (10), seja outros sujeitos a intervenções de reconstrução total, por vezes com amplo emprego do concreto armado, come no caso das intervenções no templo de Prasat Kravanh (11); em algumas obras, foram mantidas todas as lacunas figurativas, operando simplesmente através de intervenções "conservativas", como nas restaurações do complexo de Angkor Wat (12); em outras, ainda, foram reconstruídas apenas algumas partes consideradas indispensáveis do ponto de vista estático, ou absolutamente necessárias para recolocar alguns elementos originais; contemporaneamente, em outros canteiros de restauro, como no templo de Chau Say Tevoda (13), operou-se por analogia com os remanescentes, e, mesmo, através da total reconstrução do templo segundo as técnicas antigas, reproduzindo ex novo inteiros elementos decorativos, tendo o cuidado de torná-los o mais possível semelhantes aos originais. 
Os maiores danos são provocados pelo crescimento incontrolado da vegetação. Inseridos em meio a uma verdadeira floresta tropical, os templos de Angkor, mesmo se abandonados há pouco tempo, são rapidamente envolvidos pela vegetação, produzindo uma fascinante imbricação entre natureza e remanescentes monumentais, já em sua origem projetados em harmonia com a paisagem circunstante.

Um dos principais problemas concerne à eliminação, ou não, das grandes árvores (14), que num breve período envolvem os monumentos abandonados, conduzindo-os, inexoravelmente, a uma destruição certa, mas criando, também, uma imagem de absoluto fascínio. O tema é sério e, mesmo se teoricamente afim a muitos problemas de inserção da ruína na paisagem, amplamente tratados na Europa, não encontra correspondência direta na prática operacional, pois na Europa não existe uma flora comparável àquela de uma floresta tropical.

À manutenção das grandes árvores induzem diversas considerações, antes de tudo estéticas. É evidente, com efeito, como o monumento arruinado, mesmo se bastante mutilado, se torna "um fenômeno mais significativo, mais importante do que os fragmentos de outras obras de arte destruídas. Um quadro do qual se destacam pequenas partículas de cor não constitui uma unidade estética [...]. A ruína de uma construção, ao contrário, mostra outras forças e outras formas, aquelas da natureza; assim, daquilo que ainda nela vive da arte e daquilo que nela já vive da natureza, surge um novo inteiro" uma nova "unidade característica" (SIMMEL, 1919, p 125-133). (15).

Ademais, em prol de uma estética "ruinista" atuam também motivações ligadas a um inato desejo de autenticidade (16). Mas seguramente, o maior fascínio é relacionado a considerações de caráter intuitivo, como magistralmente expressado em tantas notáveis passagens de John Ruskin (17).

Para também recordar a outra face da moeda, representada pela provável desaparição de qualquer monumento abandonado à ação das forças da natureza, é possível utilizar uma célebre imagem de Thomas Paine, tão eficaz quanto as de Ruskin: "o seu coração não é tocado pela realidade da desventura, mas por aquilo que nela há de teatral e que estimula a imaginação. Tem piedade das belas penas, mas ignora o pássaro que agoniza" (PAINE, 1791) (18). Qualquer monumento de Angkor poderia, com efeito, desaparecer se aceitássemos posturas de respeito integral pelas grandes árvores que 
cresceram nos templos: quando a árvore morre, em sua queda destrói partes importantes do monumento sobre o qual cresceu, pois suas raízes se insinuam no interior de qualquer pequena fissura. Nesse caso, uma postura conservativa, levada a extremos, conduziria a paradoxais consolidações da árvore já sem vida, com efeitos ainda mais nefastos sobre o monumento. Por outro lado, é igualmente inegável que, em muitos casos, a presença de grandes árvores tenha também funções parcialmente protetoras, criando um ambiente estável em que não há mudanças sensíveis de temperatura ou umidade; ademais, alterar bruscamente uma situação consolidada ao longo do tempo é sempre arriscado e traumático. Do mesmo modo, é evidente que uma manutenção constante resolveria a priori o problema, impedindo que a vegetação assumisse proporções excessivas.

Uma linha operacional de compromisso é a adotada pelos restauradores da APSARA, formados pelo ICCROM, e pela UNESCO, que se valem de especialistas em botânica para entender o estado e a idade das plantas, de modo a planejar a remoção delas apenas quando pudessem tornar-se potencialmente danosas para a conservação do monumento. É uma postura razoável e que, de certo modo, pode ser compartilhada: evidentemente, na dialética entre a utopia da eternidade e a realidade do progressivo desfazer-se de qualquer coisa, é mais fácil tender à exaltação da permanência, pelo menos parcial, da operosidade humana do que a uma humilde submissão às forças da natureza. As ruínas são por definição, a marca de uma ação negativa e adquirem uma conotação positiva apenas ao se renunciar a uma estética que postula a inteireza de qualquer obra arquitetônica, sobretudo nesse caso, em que o aspecto dos monumentos, pela presença das grandes estruturas vegetais, não pode ser limitado a uma única visual, exatamente em virtude da participação de um elemento orgânico vivo e, portanto, em contínua mutação.

Um outro aspecto importante na preservação dos preciosos monumentos de Angkor é a sua fragilidade estrutural: a maior parte dos monumentos de Angkor é associada ao esquema do "templo montanha" (19). São estruturas praticamente desprovidas de fundação. (20). As contínuas flutuações do nível do lençol freático, entre a estação seca e aquela das chuvas, produzem, há muito tempo, movimentos significativos do terreno, com efeitos de certo modo assimiláveis àqueles de terremotos fracos e muito lentos. Por esse motivo muitos templos, pouco tempo depois de sua edificação, já haviam sido 
danificados e em numerosos edifícios são reconhecíveis as marcas de antigas restaurações.

Particularmente significativo e complexo é o caso do Baphuon, um grande templo dentro do perímetro de Angkor Thom dedicado à divindade hindu Shiva, um dos primeiros tipos de "templo montanha" (século XI); considera-se que a estrutura externa, demasiadamente alta e íngreme, já em tempos antigos não fosse capaz de suportar a resultante do enchimento interno de terra compactada. As escadas externas teriam sido acrescentadas num segundo momento com a função de verdadeiros contrafortes (21). Sucessivamente, ocorreram outros abalos e no século XV as pedras do tempo desabadas em seu lado ocidental foram recompostas para formar um gigantesco Buda reclinado, com um reemprego do material original tão interessante quanto fascinante.

A restauração moderna, iniciada nos anos 1960 e dirigida por restauradores franceses da EFEO, tende a uma desmontagem integral do templo (com exceção, afortunadamente, da colossal representação do Buda), com vistas a uma sucessiva recomposição. Mais de 300.000 blocos foram deslocados e numerados (22) até 1970, quando os eventos políticos obrigaram a missão a abandonar o monumento. Em 1995 os trabalhos, que ainda estão em andamento, foram retomados (23): às dificuldades iniciais, acrescentaram-se aquelas ligadas à recomposição de um imenso quebracabeça de pedras esparsas pela floresta sem poder contar com a ajuda dos levantamentos precedentes, que se perderam. Além do mais, atrás do grande Buda reclinado, existia originalmente um longo corredor com as entradas (gopura) decoradas com um importante ciclo de baixos-relevos que hoje se decidiu tornar novamente visível, reconstruindo parte das abóbadas desabadas. Para isso, alguns blocos utilizados no século XV para compor a figura do Buda (e, antes ainda, pertencentes ao ciclo hindu) serão recolocados na sua posição originária, substituindo-os por cópias modernas. Desse modo, quis-se conservar a imagem do monumento que nos chegou nos últimos cinco séculos e, ao mesmo tempo, recompor uma importante obra-prima da história da arte antiga. A nova sistematização do templo assim restaurado, proporá, portanto, dois estratos da história entre si incompatíveis, porque baseados no uso da mesma matéria, tornando novamente acessível um espaço já perdido. Conceitualmente não se trata de uma repristinação tout court da primeira configuração do templo (que provavelmente não irá além do nível do corredor), nem de uma anastilose banal, mas de uma intervenção crítica que aceita, nesse caso, não a perda das adições, mas a parcial duplicação da 
matéria. $\mathrm{O}$ fato de as duas imagens estarem em dois planos diversos, um externo (o Buda reclinado) e outro interno (a gopura), deveria torná-las conciliáveis entre si.

Na maior parte das intervenções realizadas no grande parque arqueológico de Angkor, quase sempre os restauradores modernos optaram por anastiloses integrais, com êxitos amiúde insatisfatórios do pondo de vista estético. O tema da admissibilidade, ou não, de operações do gênero foi amplamente tratado no passado, com opiniões não raro contrastantes. (24)

Cesare Brandi (2004, p. 82) notava como "a obra de arte reduzida a ruína, pelo fato de qualificar uma paisagem ou uma zona urbana [...] não é de modo algum ligada à sua primitiva unidade e inteireza, mas é, sim, conexa à sua mutilação atual" e é

[...] por isso um erro crer que toda coluna despedaçada possa ser reerguida e recomposta de modo legítimo quando, ao contrário, o ambiente onde isso deveria acontecer já atingiu, historicamente e esteticamente, uma acomodação que não deve ser destruída nem para a história nem para a arte. (BRANDI, 2004, p. 82). (25)

Esse problema é muito evidente no "Terraço do Rei Leproso" (Angkor Thom), onde os blocos que permaneceram por anos abandonados na selva foram recolocados ao lado de outros escavados há pouco tempo e, portanto, num estado de conservação muito diverso e visivelmente dissonante (26).

É evidente a abordagem diversa entre as restaurações feitas nas primeiras décadas do século XX aquelas dos anos 1970 e as atuais, mesmo se diferentes entre si. O fato de, com uma distância de poucos anos (pelo menos em relação à vida de monumentos tão antigos), mudar drasticamente de opinião, deveria fazer com que qualquer um que queira aproximar-se dos temas da restauração refletisse sobre sua necessária relação com opiniões e avaliações que mudam com o tempo, como demonstram os diferentes êxitos práticos e operacionais, que oscilam entre recomposições integrais e atentas manutenções conservativas. Ainda mais porque nos templos de Angkor são impostas escolhas extremas, pois existem freqüentemente situações de degradação excepcional que, quase nunca, consentiriam intervenções de simples congelamento, pelo menos ao se levar em consideração o parecer dos especialistas que ali trabalham. 
O único modo seguro de destrinchar um âmbito tão complexo é partir de princípios compartilhados. O objetivo comum é a correta interpretação do passado e a transmissão ao futuro da herança que chegou até nós, de modo que nossos sucessores possam estudar, interpretar e usufruir as mesmas obras que vemos hoje. Isso significa atuar respeitando a especificidade da obra sem destruir nada, conservando o mais possível e adotando para os acréscimos rigorosos critérios de compatibilidade (física, química e sobretudo estética) com o original. Na base de tudo deve estar sempre um profundo e pormenorizado conhecimento do monumento e de seu sítio, histórico-crítico e também científico e social. Por isso alguns especialistas internacionais presente há décadas em Angkor estão agora trabalhando num código deontológico para intervenções, específico para esse particularíssimo parque monumental. Somente uma abordagem comum, embasada numa regulamentação específica de técnicas, métodos e materiais pode evitar os danos gerados por restauros inadequados, danos que infelizmente Angkor sofreu demasiadas vezes no passado.

É necessário ainda recordar a importância do contexto social, extremamente incômodo, no qual se atua. Um recente estudo realizado pelo WFP (World Food Programme) evidenciou que a província de Siem Reap é a mais pobre do Camboja. É necessário, pois, planejar um correto uso dos meios tutelando e valorizando conjuntamente os monumentos e seu contexto social e cultural. A responsabilidade que nós, ocidentais, temos ao atuar de maneira conscienciosa para conservar os monumentos de Angkor é sobretudo aquela de transmitir a experiência amadurecida em mais de dois séculos de experiências na tutela dos bens culturais na Europa, aprendendo com nossos erros passados. Os graves erros cometidos no século passado, com efeito, não são mais justificáveis hoje. O risco mais evidente é apoiar indiferentemente, como ocorreu na Itália, qualquer investimento que seja coerente com um desenvolvimento rápido que, como bem sabemos, quase nunca se associa a escolhas atentas e apuradas, escolhas de defesa dos estratos sociais mais fracos e dos bens culturais.

\section{As diversas abordagens européias sobre a conservação das superfícies}

A manutenção e o restauro das superfícies marmóreas seguem, desde há muito, modalidades que derivam do efeito final que se deseja obter. Não se trata de um modo de operar unívoco; ao contrário, se confrontássemos as várias intervenções feitas ao redor do mundo, elas poderiam parecer, mesmo, muito diferentes entre si. 
É exemplar o caso da série chamada amorini [cupidos] de Antonio Canova - quatro esculturas realizadas entre 1786 e 1797 pelo célebre artista italiano -, hoje dispersas em vários países europeus: o Amorino Lubomirski (1786-88) conservado no Castelo Lan'cut na Polônia (Muzeum Zamek w Łańcucie), o Amorino Campbell (1787-89) na Abadia Anglesey de Cambridge, o Amorino Latouche (1789) na Galeria Nacional da Irlanda em Dublin e o Amorino Yussupov (1793-97) no Hermitage de São Peterburgo.

São quatro versões do mesmo tema, replicado várias vezes por Canova, por pedido explícito de seus muitos comitentes (originalmente existia ainda um quinto cupido, que Canova denominou Apollo, realizado em 1797 para o francês Juliot, infelizmente desaparecido e conhecido somente através da cópia existente no Palácio d'Accursio em Bolonha).

A primeira das quatro obras retrata o príncipe Lubomirski e foi encomendada a Canova na primavera de 1786 pela princesa Elzbieta Czartoriska (viúva de Stanislaw Lubomirski) em Roma, juntamente com o futuro sobrinho, Henryk, de oito anos, numa das etapas de seu afastamento forçado da Polônia, por causa das significativas tensões com o novo rei, Stanislaw Poniatowski. A estátua, completada entre 1787 e 1788 (provavelmente modelada num mármore antigo, reaproveitado, adquirido pelo copiador e restaurador Carlo Albacini) retrata o vulto do jovem príncipe num corpo idealizado e adulto que, com suaves contornos, repropõe a iconografia clássica de Eros (uma cópia romana do século II d.C., a partir de um original atribuído a Lisippo, foi descoberta na Vila d'Este, em Tivoli, nas cercanias de Roma), com arco e aljava, transfigurando assim o jovem príncipe, conhecido pelos seus belíssimos traços, na imagem do deus do amor.

A sorte da estátua foi tal que, além da princesa Lubomirski, diversos nobres europeus encomendaram a Canova ulteriores cópias. $\mathrm{O}$ artista aproveitou a ocasião para realizar variantes sucessivas que paulatinamente o levaram a aperfeiçoar o tema.

A primeira delas foi encomendada em 1787 pelo coronel inglês John Campbell que, visitando o ateliê romano de Canova (ao qual já havia encomendado o mais conhecido Amor e Psique) teve a oportunidade de ver o Amorino Lubomirski em execução; a obra foi realizada a partir do modelo precedente, substituindo o vulto do jovem príncipe por uma imagem idealizada, mais consoante com a busca formal fortemente idealizada do artista. Esse segundo cupido chegou a Londres em 1790 para depois ser transferido 
para a residência Campbell em Stackpole Court em Gales. Um terceiro cupido de mármore foi realizado entre 1789 e 1791 para John La Touche, filho de um rico banqueiro irlandês que, vendo a escultura feita para o coronel Campbell, obteve de Canova o compromisso de realizar uma réplica. A quarta versão, enriquecida por elegantes asas (considerada por Canova "la meilleure que j'ai jamais faite dans ce genre" (27)) foi realizada para o príncipe Nikolaj Borisovich Jussupov, conhecido colecionador de arte russo. As duas obras - o cupido e um Amor e Psique - chegaram em São Petersburgo em 1802; e em 1810 foram transferidas a uma propriedade ao sul de Moscou para enfim, depois de muitas travessias, chegar, apenas em 1926, ao museu Hermitage.

Todos os cupidos, apesar de ligeiramente diversos, deviam ter na origem, presumivelmente, o mesmo tipo de acabamento superficial. Agora, ao contrário, mostram diferenças evidentes, no que respeita tanto aos aspectos cromáticos, quanto à refração da luz, contrariamente às intenções originárias do artista que, pelo que se sabe através da documentação, desejaria obter resultados praticamente idênticos; ademais Canova realizou as quatro obras num arco temporal contínuo e limitado (pouco mais de uma década), empregando sempre técnicas e materiais quase idênticos, todas circunstâncias que não justificam, de nenhum modo, as fortes alterações que se vêem hoje. Por isso, essas variações são em grande parte atribuíveis às vicissitudes sofridas pelas obras e, sobretudo, pelas escolhas distintas no que concerne à conservação e limpeza das superfícies marmóreas feitas nos últimos dois séculos.

Deve-se recordar, com efeito, que durante o século XIX se delinearam na Europa pelo menos duas posições teóricas, antitéticas, de restauro, que podem ser associadas, respectivamente, às idéias do arquiteto francês Eugène Emmanuel Viollet-le-Duc (18141879) - que teorizou intervenções que restituíssem aos monumentos uma imagem completa e uma unidade estilística, mesmo se fantasiosa (28) - e às idéias românticas do intelectual inglês John Ruskin (1819-1900) - contrário, polemicamente, a intervenções de "restauro" que alterassem a imagem autêntica que o monumento assumiu com o tempo, que ele considerava dever ser conservada em toda a riqueza de suas estratificações e alterações (29). Portanto, por um lado, tem-se uma linha operacional que privilegia um aspecto "limpo" e uma unidade formal da obra, ou seja, a componente estética em detrimento da histórico-documental, situando a própria intervenção no bem a ser restaurado em continuidade com os presumíveis autores 
iniciais, e, por outro, uma posição estética sensível ao fascínio das superfícies marcadas pelo tempo e muito atenta à conservação dos sinais originais daquilo que foi herdado pela história, que é observado com respeitoso distanciamento.

Na Itália, diversamente, reforçou-se uma linha operacional definida como "intermediária", que conjugava, com a exigência de restabelecer a unidade formal do monumento, uma série de prescrições derivadas de cuidadosas pesquisas histórico-arquivísticas, com o intuito de respeitar a autenticidade do bem no qual se realizava a intervenção. Uma postura cultural tipicamente italiana, em que refinadas formulações teóricas se uniam, há tempos, às exigências práticas da tutela e restauro de um copioso patrimônio de monumentos antigos herdados ao longo dos séculos; essa postura teve uma notável validação também em âmbito internacional, como demonstra a maior parte dos enunciados da própria Carta de Restauração de Atenas de 1931. (30).

De modo análogo, a essas distintas linhas teóricas e aos seus atuais desdobramentos é possível tentar reconduzir as variações encontradas nos quatro cupidos com as diversas posturas de preservação.

Observando de perto as quatro estátuas e ordenando-as numa hipotética progressão baseada no aspecto de suas superfícies, passa-se, com efeito, de uma imagem fortemente marcada pelo tempo do Amorino Campbell (a estátua, no passado, passou por notáveis alterações por causa de uma longa permanência ao ar livre), àquela bem conservada e com uma "agradável" pátina, a do Príncipe Lubomirski como Amor (desde 1790 exposta na Polônia, no Castelo de Lan'cut, hoje Muzeum Zamek w Łańcucie: não por acaso a única das quatro estátuas que sempre permaneceu em seu lugar originário e, portanto, respeitando as mais óbvias indicações de conservação), às superfícies vistosamente brancas do Amorino Yussupov proveniente do Hermitage de São Petersburgo, até a do Amorino La Touche, mais próxima do gosto dos colecionadores privados que privilegiam uma imagem em estado de nova (a escultura, redescoberta nos anos 1990 por um particular, depois de ter sido por longo tempo considerada perdida, foi adquirida e depois restaurada, em 1998, sob a direção de Sergio Benedetti, da Galeria Nacional da Irlanda). 
O tema é de grande interesse pois ainda com o próprio Canova em vida foram muitas as polêmicas sobre o uso de tratamentos secretos ou acabamentos superficiais particulares utilizados pelo artista em suas obras para torná-las mais verossímeis (31).

A primeira consideração, quase desconcertante em sua obviedade - mesmo se igualmente desconsiderada pelos contínuos deslocamentos de importantes obrasprimas entre os maiores museus do mundo - é que o melhor modo de conservar uma obra é o de mantê-la em seu ambiente originário, sem nenhuma intervenção de restauração, mas apenas através de contínuas e delicadas manutenções.

É lícito questionar, portanto, sobretudo nesse caso em que é notória a atenção obsessiva que Canova tinha pelo acabamento das superfícies de suas obras, se qualquer restauração muito agressiva não modifica para sempre o aspecto "correto" das estátuas.

A reflexão, derivada da evidência do aspecto nem sempre convincente dos quatro cupidos de Canova, pode ser, com efeito, estendida facilmente à análise atual das diversas orientações teóricas da disciplina do restauro e da conservação na Europa, assim como às diversas escolhas de tratamento das superfícies externas das obras arquitetônicas.

Certamente enfrentar um debate tão complexo a partir da observação das quatro obrasprimas da escultura de Antonio Canova pode parecer fora de propósito, pois nem todos estão de acordo sobre a unidade de método do restauro para as obras de arte e para a arquitetura. No entanto, deve-se recordar que os princípios, se tal o são, devem estar acima das particulares diferenças operacionais, devendo definir os valores e as finalidades que devem ser a base de toda intervenção. Não deveria haver motivo - uma vez que se esteja de acordo sobre aquilo que se entende por tutela, conservação e restauro - pelo qual se devam invocar métodos, ou melhor, princípios diversos apenas para as obras de arquitetura. Com efeito, qualquer arquiteto concordará facilmente com Cesare Brandi quando afirma que "também a arquitetura, se tal, é obra de arte" (BRANDI, 2004, p. 131) (32): quando muito será necessário questionar-se sobre o que fazer com tantas construções que não atingem o status de obra de arquitetura. Não por acaso, com efeito, o tratamento das superfícies arquitetônicas externas representou, nos últimos anos, um tema bastante debatido e talvez aquele que hoje melhor evidencia as 
diferenças entre as várias vertentes operacionais. Passa-se da posição de absoluto respeito pelas marcas do tempo, vistas como portadoras de irrenunciáveis valores estéticos e documentais a outras de desenvolta remoção dos acabamentos externos, entendidos com superfícies de sacrifício destinadas a serem renovadas periodicamente. A reflexão derivada da análise das quatro notáveis esculturas de Canova poderia, desse modo, ser estendida, por analogia, a muitos outros casos. Seguramente é uma oportunidade para evidenciar a diversidade dos resultados obtidos aplicando métodos distintos que, se fossem todos igualmente válidos, teriam, como natural conseqüência, a aceitação de uma margem, não indiferente, de relatividade para qualquer intervenção, enquanto quase certamente, pelo menos no caso de Canova, o artista havia imaginado somente uma facies para as suas esculturas. Uma solução possível é aquela de propor intervenções endereçadas a um equilíbrio são entre as instâncias estéticas e aquelas histórico-conservativas, seguindo a vertente teórica definida como "crítico-conservativa". Essa posição representa o estágio atual da evolução de uma pesquisa originada na Itália a partir dos anos 1950 com o "restauro crítico" e que, numa sucessão ininterrupta, se desenvolveu e teve continuidade em grande parte na Universidade de Roma La Sapienza, de Cesare Brandi até Renato Bonelli, Giuseppe Zander, Gaetano Miarelli Mariani e Giovanni Carbonara.

De todo modo, a conservação integral das marcas do tempo, quando possível na ausência de fenômenos ativos de degradação, representa uma ação correta do ponto de vista ético que permitirá aos vindouros herdar um bem íntegro - em seus valores materiais e estéticos intrínsecos - que poderão estudar e sobre o qual poderão operar de modo pleno. Isso não pode ser dito, por exemplo, de uma escolha de remoção de pátinas (formalmente proibida na Itália pela Carta de Restauração de 1972) que é sempre irreversível e poderia revelar-se, no futuro, um grave erro, não apenas pela perda de importantes valores estéticos (mesmo se sempre relacionados a avaliações que mudam com o tempo), mas também de informações materiais que atualmente não podem ser reconhecidas ou indagadas de modo adequado. 


\section{Imagens}

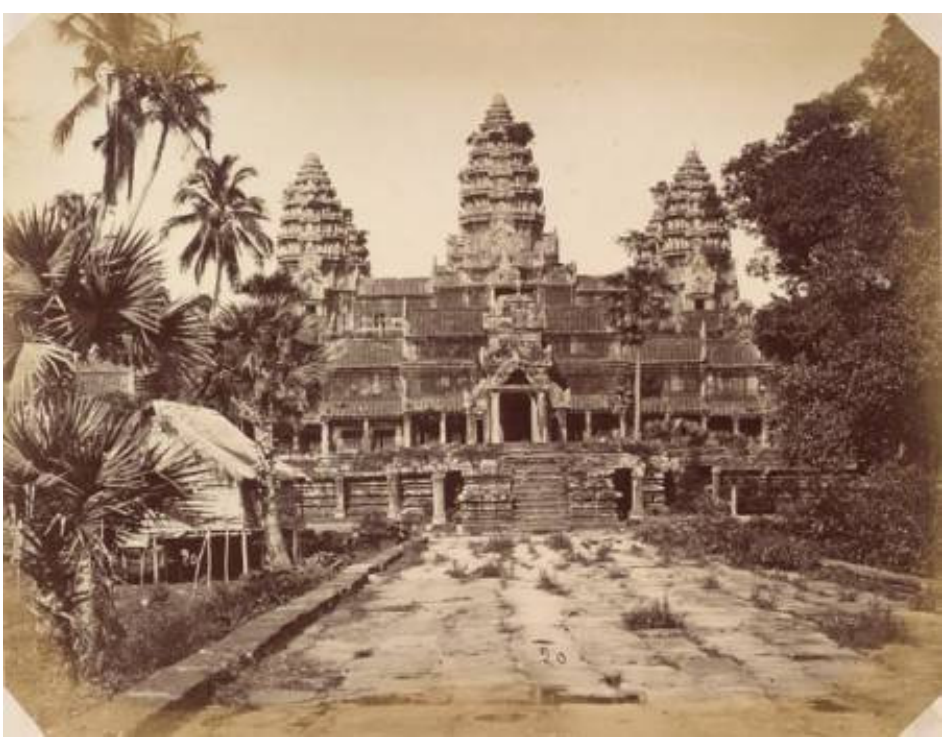

FIGURA 1 - Angkor Wat em 1866 (foto Emile Gsell).

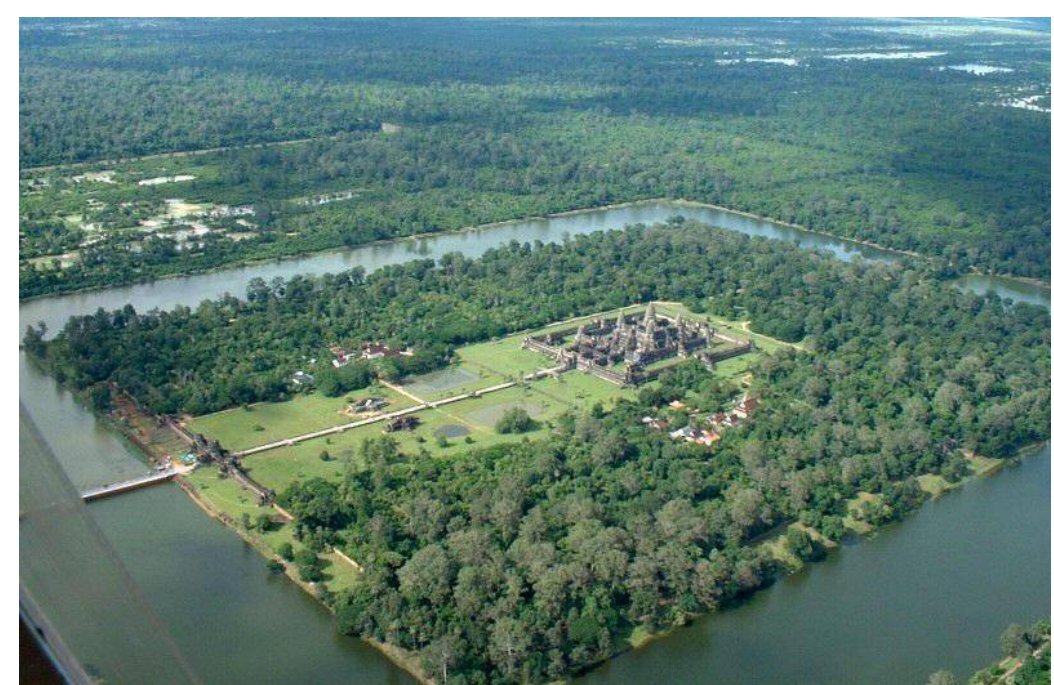

FIGURA 2 - O complexo de Angkor Wat e seus canais.

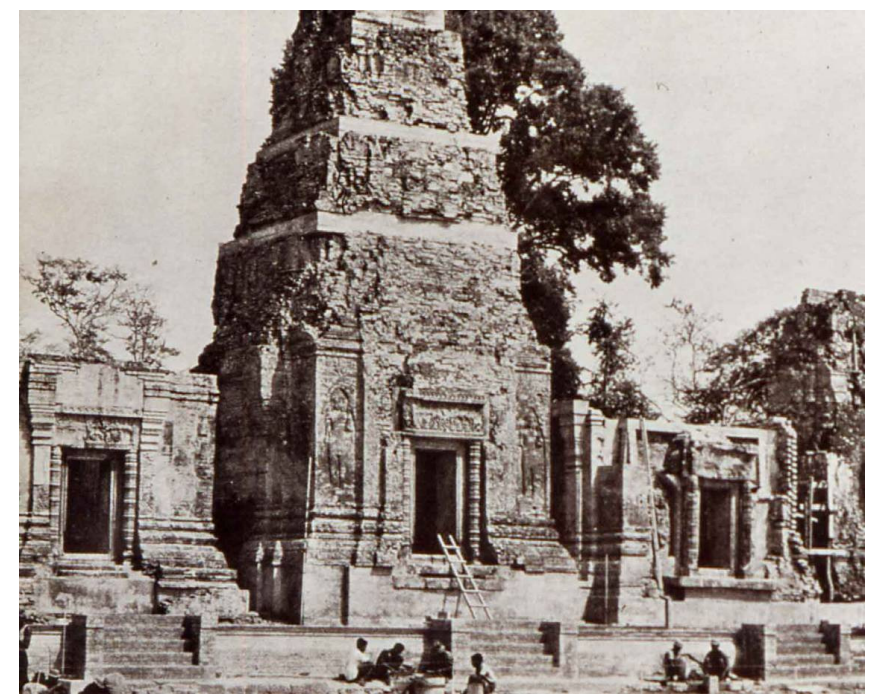

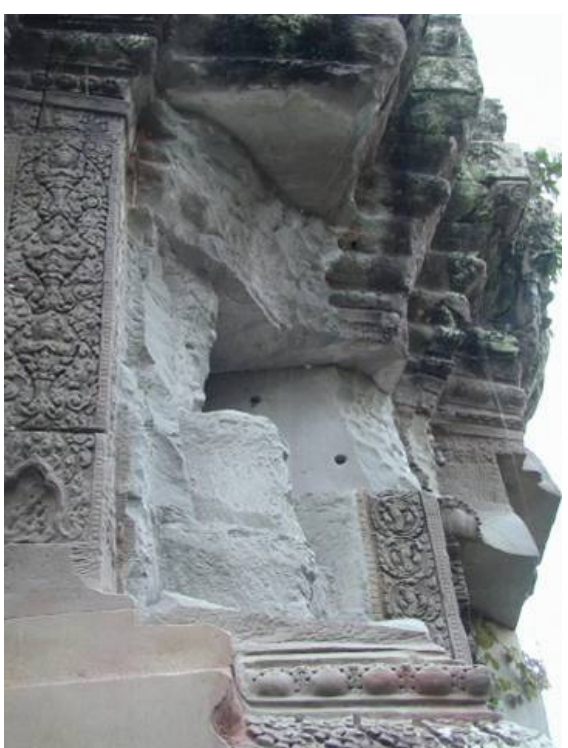

FIGURA 3 - Danos sofridos pelos monumentos.
FIGURA 4 - Restauro executado pelos

franceses em Prasat Kravanh (1920-1930), com amplo emprego do concreto armado. 


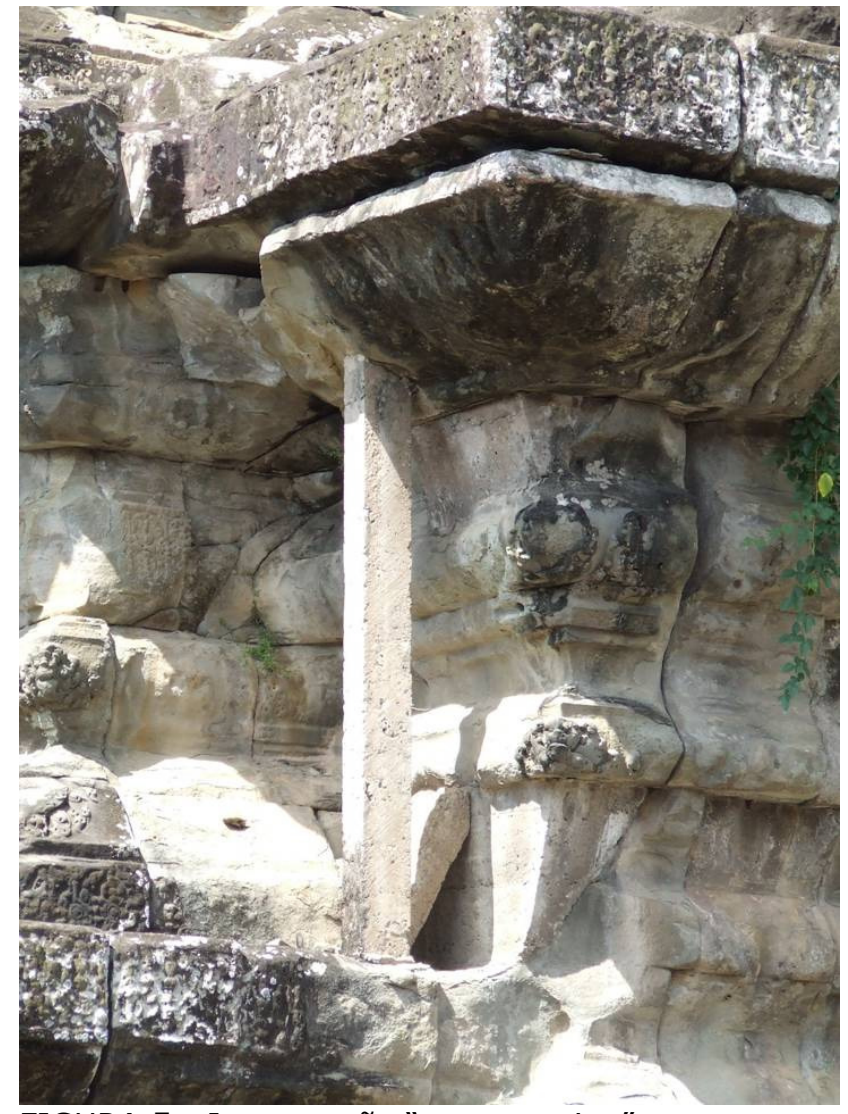

FIGURA 5 - Intervenção "conservativa".

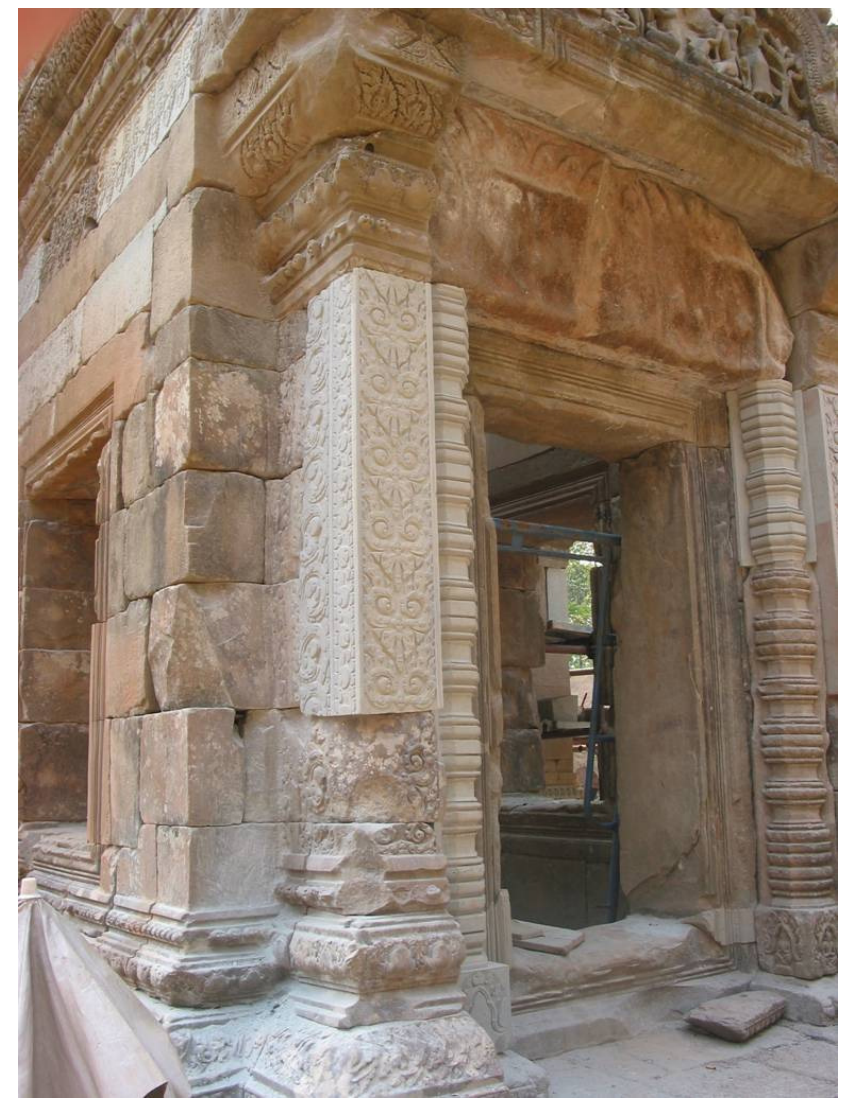

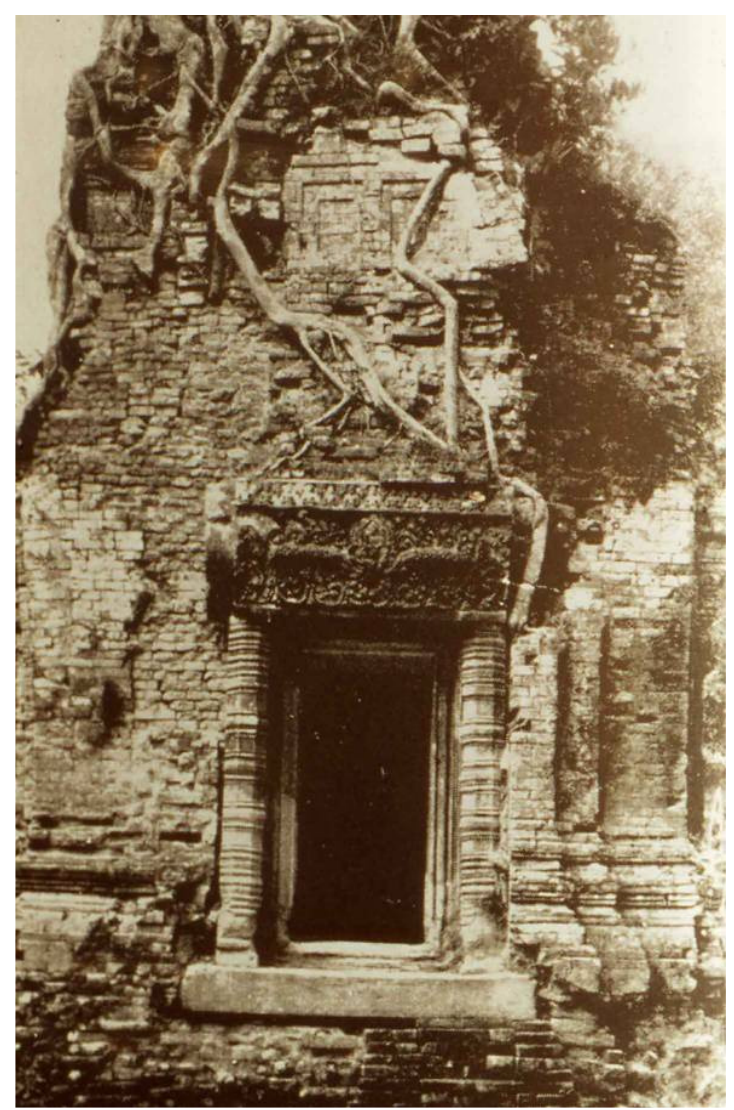

FIGURA 6. Presença de vegetação de grande porte em Prasat Kravanh (1920-1930).
FIGURA 7 - Chau Say Teroda, restauros coordenados pelo Chinese Government Team for Safeguarding Angkor, com extensos trabalhos de completamento. 


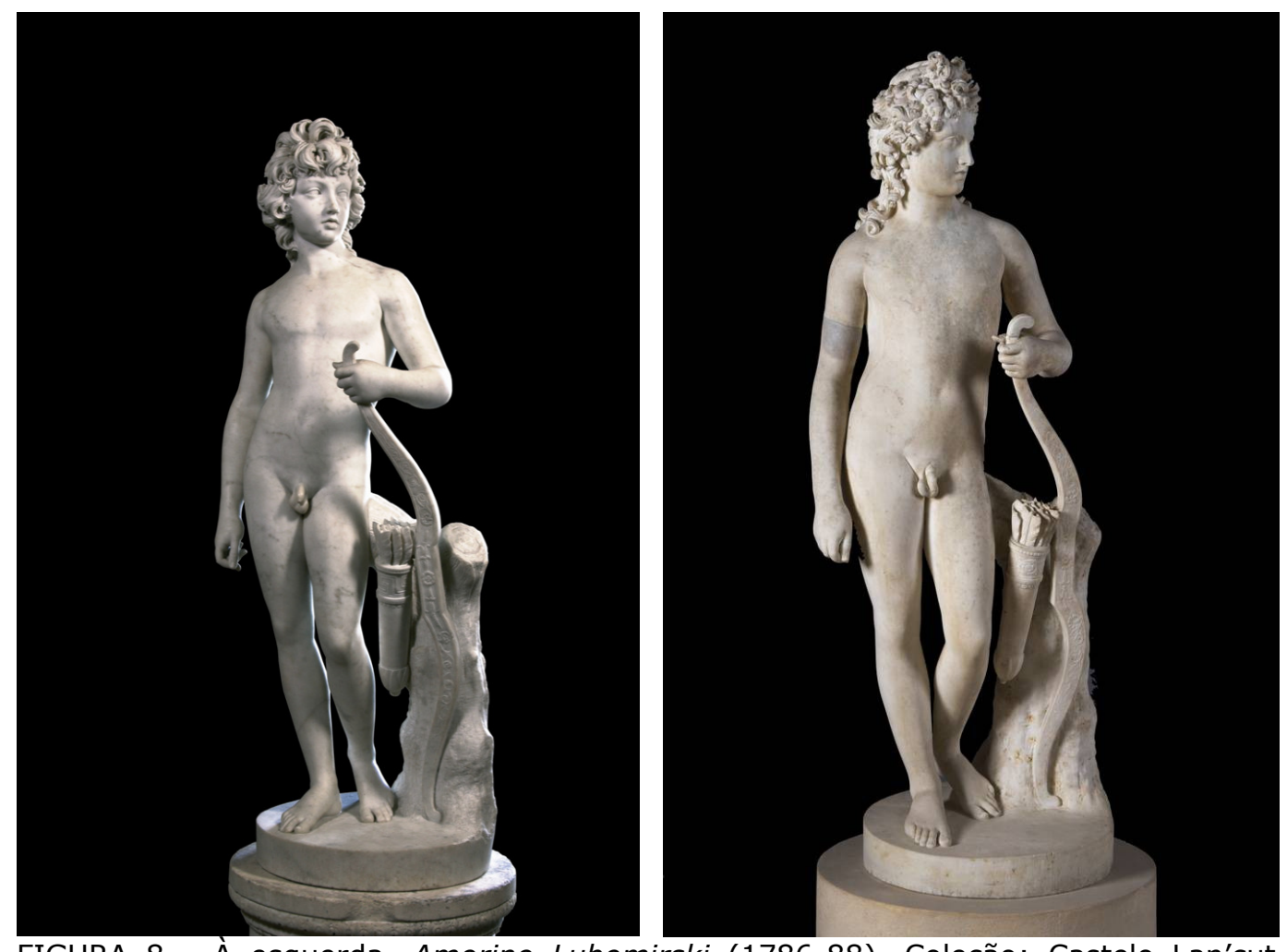

FIGURA 8 - À esquerda, Amorino Lubomirski (1786-88). Coleção: Castelo Lan'cut, Polônia. À direita, Amorino Campbell (1787-89). Coleção: Abadia Anglesey, Cambridge.
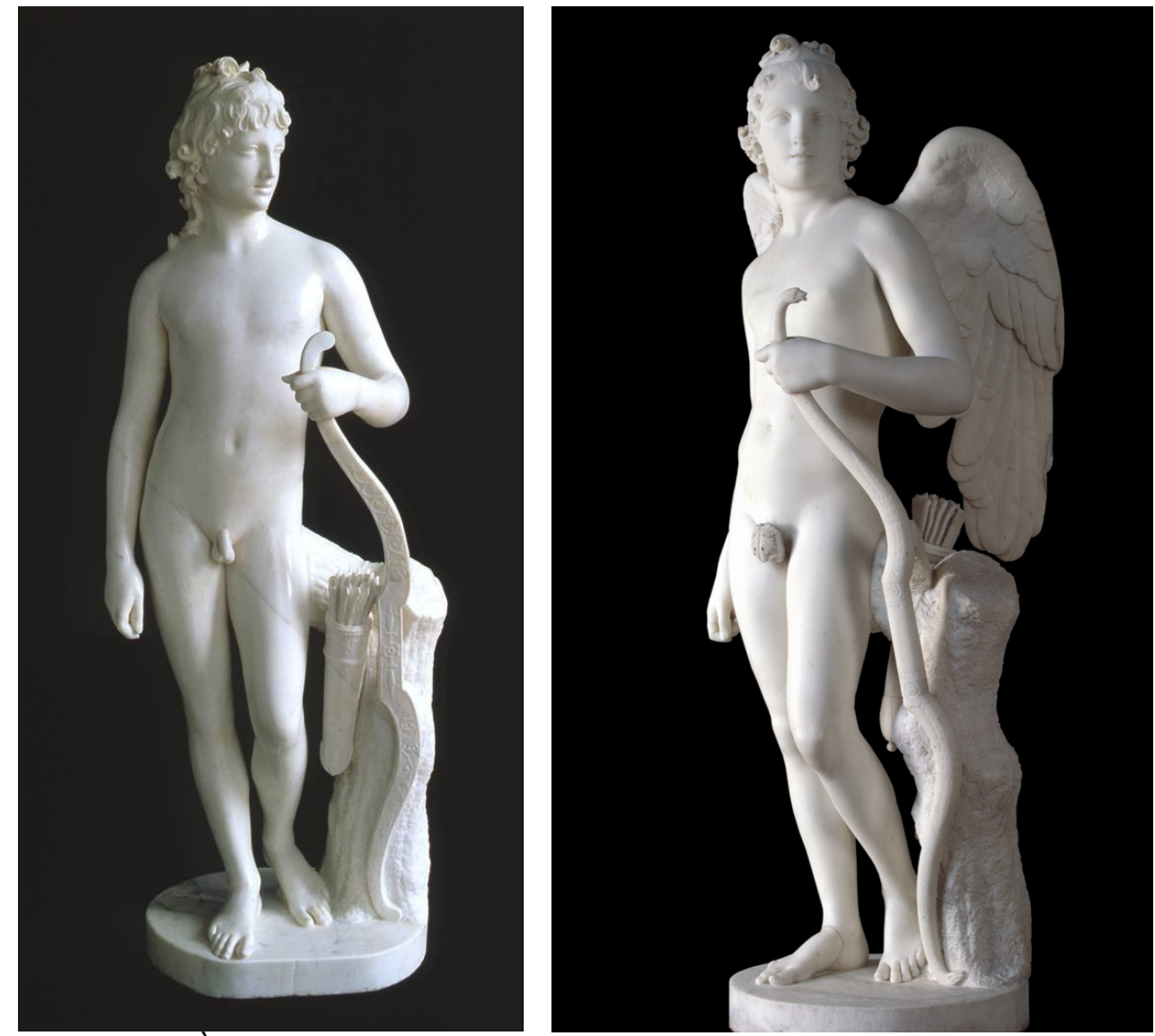

FIGURA 9 - À esquerda, Amorino Latouche (1789). Coleção: Galeria Nacional da Irlanda, Dublin. A direita, Amorino Yussupov (1793-97). Coleção: Hermitage, São Peterburgo. 


\section{Notas}

(1) Os casos de estudos presentes neste texto foram apresentados por Alessandro Pergoli Campanelli num ciclo de conferências no CPC-USP, entre os dias 8 e 11 de agosto de 2008. Durante o ciclo - que foi parte integrante da disciplina do programa de Pós-Graduação da FAUUSP "AUH 5816 - Metodologia e Prática da Reabilitação Urbanística e Arquitetônica", sob responsabilidade das Profas. Dras. Beatriz Mugayar Kühl e Maria Lucia Bressan Pinheiro - foram abordados temas relativos à restauração na atualidade, e tratadas as principais orientações teóricas e suas repercussões na prática, através da análise de variadas intervenções. N. da T.

(2) O português Diego de Couto (em um texto de 1550, publicado apenas em 1958) faz referência ao rei Ang Chan I (1505-1556), que teria descoberto os muros de um imenso templo (Angkor Wat) durante uma caçada com elefantes (cfr. DAEGENS, B. Angkor heart of an Asian Empire. New York: Abrams, 1995, p. 133-135). O missionário franciscano Marcelo de Ribadenera (Historia de las Islas del Archipiélago, y Reyno de la Gran China, Tartaria, Cochinchina, Malaca, Siam, Camboxa y Japón, y de lo sucedido en ellos a los Religiosos Descalzos de la Orden del Seráfico Padre San Francisco, de la Provincia de San Gregorio de las Philipinas, Barcelona 1601) descreve Angkor Wat como "as ruínas de uma antiga cidade que se poderia dizer construída pelos romanos, ou por Alexandre, o Grande". Sucessivamente, muitos outros descreveram as ruínas de Angkor, mas as suas breves descrições são pouco conhecidas e tiveram escasso reconhecimento no Ocidente, apesar da riqueza e da extensão do sítio. Entre elas, encontra-se o diário do padre Charles-Emile Bouillevaux (Voyage en Indochine 1848-1856, L'Annam et le Cambodge), publicado na França um ano antes da expedição de Mouhot.

(3) Somente em 1949 o Camboja conquistou o seu primeiro governo autônomo e depois, em 1953, a independência do controle francês.

(4) A EFEO foi constituída em 1898 em Hanói, capital da então Indochina francesa.

(5) Essa área é muito importante para a história do Camboja: ainda que em outras zonas da nação existam ruínas de antigas civilizações (Sambor Pre Kuk, capital do reino Chela, que remonta ao século VII d. C., por exemplo), Angkor representa o início do verdadeiro momento de unificação política do país, ocorrida com o coroamento do Rei Jayavarman II (802-850 d.C.) que constituiu um reino autônomo, com capital em Hariharalaya, próxima à atual Roluos. O Rei Yashovarman I (889-915 d.C.) deslocou depois a capital para Yasodharapura, cerca de $20 \mathrm{~km}$ a oeste, perto da atual Phnom Bakheng, constituindo a primeira cidade de Angkor.

(6) Importantes obras de arte retiradas dos monumentos que decoravam, saíram ilegalmente do Camboja para reaparecer ocasionalmente em alguns importantes museus europeus e norte-americanos - e nem sempre é possível a sua recuperação legal - enquanto da maior parte não se tem a menor pista. Naqueles anos, os monumentos de Angkor sofreram uma série de danos graves que, no entanto, em comparação às destruições ocorridas na Europa durante a Segunda Guerra Mundial, são bastante limitadas.

(7) O decreto estabelece cinco zonas. A primeira, "Monumental Sites" [Sítios Monumentais], concerne às áreas arqueológicas consideradas as mais significativas (na prática, o perímetro do parque), em cujo interior vige o nível de proteção máximo. A segunda, "Protected Archaeological Reserves" [Reservas Arqueológicas Protegidas], são as áreas limítrofes à primeira zona, ricas de remanescentes arqueológicos ainda não escavados, em cujo interior não é permitido construir com concreto armado. Na terceira zona, "Protected Cultural 
Landscapes" [Paisagens Culturais Protegidas], recaem as áreas com características paisagísticas "protegidas", mesmo se em seu interior a contínua e frenética expansão do novíssimo complexo turístico de Siem Reap está de fato saturando todos os centímetros quadrados com construções modernas. A quarta zona, "Sites of Archaeological, Anthropological or Historic Interest" [Sítios de Interesse Arqueológico, Antropológico e Histórico] concerne às áreas que incluem os outros sítios arqueológicos (considerados, com maior ou menor razão, menos interessantes do que aqueles do parque monumental), para os quais são previstas ações de salvaguarda ainda mais limitadas e que, de certo modo, favorecem a pesquisa e o turismo. Por fim, a última zona, "Socio-economic and Cultural Development Zone of the Siem Reap region" [Zona de Desenvolvimento Socioeconômico e Cultural da Região de Siem Reap], envolve todas as áreas restantes.

(8) O Comitê Internacional, gerido pela UNESCO e pela APSARA, com o patrocínio das embaixadas da França e do Japão, avalia e aprova todos os projetos de restauro relativos à área monumental, valendo-se de um comitê técnico composto por eminentes especialistas internacionais (Pierre André Lablaude, Hiryuki Suzuki, Giorgio Croci, Mounir Bouchenaki).

(9) No grande parque arqueológico de Angkor operam, além da APSARA, muitas instituições provenientes de numerosos países estrangeiros - Archaeological Survey of India , Chinese Government Team for Safeguarding Angkor (CSA), École Française de l'Extrême-Orient (EFEO), German Apsara Conservation Project (GACP), Japanese Government Team for Safeguarding Angkor (JSA), Sophia University Angkor International Mission (Japan), The University of Sydney, The Greater Angkor Project (GAP), The Living with Heritage Project (LWH), World Monuments Fund (WMF) etc. - além de muitíssimos especialistas provenientes de quase todo o mundo.

(10) As primeiras restaurações remontam às intervenções de H. Marchal (1927-1932) da EFEO, continuadas com as anastiloses parciais de M. Glaize, em 1939, e hoje prosseguidas, em colaboração com a APSARA, pelo estadunidense World Monuments Fund.

(11) As primeiras restaurações foram feitas pela EFEO sob a direção de H. Marchal, entre 1929 e 1931 , e G. Trouvé em 1935; no pós-guerra, B. P. Groslier realizou intervenções de 1962 a 1966.

(12) As primeiras restaurações modernas remontam aos trabalhos de Jean Commaile para a EFEO. Nas restaurações recentes, coordenadas pelo German Apsara Conservation Project (Fachhochschule Köln, Fakultät für Kulturwissenschaften, coordenador do projeto Hans Leisen), foi executado o levantamento, com o escaneamento de centenas de metros de baixos-relevos, para realizar a análise da degradação e propor intervenções mínimas de limpeza e consolidação das superfícies, em curso desde 1995.

(13) Restauros feitos pelo CSA (Chinese Government Team for Safeguarding Angkor).

(14) Ademais ficus virens e tetrameles nudiflora.

(15) SIMMEL, G. Die Ruine in Philosophische Kultur. Leipzig: Alfred Kröner Verlag, 1919, p. 125 -133. Tradução italiana de M. Monadi: SIMMEL, G. Saggi di cultura filosofica. Milano: Longanesi, 1985, p. 108-114.

(16) "[...] a vista das ruínas nos faz, de modo fugaz, intuir a existência de um tempo que não é aquele do qual falam os manuais de história ou que as restaurações buscam ressuscitar. É um tempo puro, não datável, ausente desse nosso mundo de imagens, de simulacros e de reconstruções, desse nosso mundo violento cujos 
restos não têm mais tempo de se tornar ruínas" (AUGÉ, M. Le temps en ruines. Paris: Galilé, 2003; tradução italiana: AUGÉ, M. Rovine e macerie. Il senso del tempo. Torino: Bollati Boringhieri, 2004).

(17) "em arquitetura a beleza induzida e acidental é mais comumente inconsistente com a preservação do caráter original, e o pitoresco é, portanto, buscado na ruína, e considerado como decadência. No entanto [...] consiste na pura sublimidade dos orifícios, ou das fraturas, ou das manchas, ou da vegetação, que assimilam a arquitetura à obra da Natureza" (The lamp of memory; In: RUSKIN, John. The seven lamps of architecture, New York: Wiley \& Halsted, 1857, p.160).

(18) PAINE, T. Being an Answer to Mr. Burke's Attack on the French Revolution. In: The rights of Man. Baltimore: J. Johnson, 1791. Tradução italiana: PAINE, T. I diritti dell'uomo e altri scritti politici [organização T. Magri]. Roma: Editori Riuniti, 1978.

(19) São grandes pirâmides em degraus, constituídas por uma parte central de laterito revestida por blocos de arenito (transportados de pedreiras distantes, até mesmo, dezenas de quilômetros) que eram sucessivamente esculpidas como se o edifício inteiro fosse um imenso monólito. Uma série redundante e simétrica de rampas tinha a função de conter as resultantes internas. No entanto, por causa da instabilidade inerente num símile sistema, muitos templos desabaram parcialmente ainda em tempos antigos.

(20) Os antigos construtores Khmer não empregavam sistemas mais "resistentes", como o arco ou as abóbadas comumente difundidas no Ocidente, mas cobriam as passagens e as galerias com "abóbadas aviajadas" ou endentadas (em inglês "corbelled vault"), realizadas com elementos horizontais deslocados progressivamente em direção ao centro.

(21) A edificação de Baphuon precede aquela de muitos outros templos e é provável que, exatamente por esses erros, os arquitetos antigos tivessem aprendido a dimensionar de outro modo os templos e a acrescentar, como em Angkor Wat, as escadas já na primeira fase da construção.

(22) Sob a direção de B. P. Groslier.

(23) Sob a direção de. J. Dumarcay e P. Royère.

(24) Cesare Brandi, contrário à anastilose do Templo E de Selinunte asseverava que nas antigas colunas "uma vez levantadas [...] nenhuma dessas rochas corresponderá, então, com sua colega e teremos, em vez de um fuste único, conceitualmente monolítico [...], toda uma série de rodelas sobrepostas, com as bordas arredondadas e consumidas, que apenas de modo aproximativo afixarão uma sobre a outra" (BRANDI, Cesare. II restauro. Teoria e pratica [organização M. Cordaro]. Roma: Editori Riuniti, 1994, p. 161).

(25) BRANDI, Cesare. Teoria da restauração. Cotia: Ateliê, 2004, p. 82.

(26) Para os atuais arquitetos da EFEO que estão coordenando os trabalhos, existe a circunstância que, nesse caso, se trata de uma intervenção interrompida pelos eventos bélicos e projetada nos anos 1970, quando a tendência a desmontar e consolidar os templos estava em seu auge. 
(27) "A melhor que eu já fiz desse gênero". Carta a Jussupov de 15 novembro de 1794, Museu Cívico de Bassano del Grappa, manuscritos, MsC, I-XI-I/221; apud: PAvanello, G. (org.) Antonio Canova: disegni e dipinti del Museo civico di Bassano del Grappa e della Gipsoteca di Possagno presentati all'Ermitage. Milão: Skira, 2001, p. 42.

(28) "Restaurar um edifício não é mantê-lo, repará-lo ou refazê-lo, é restabelecê-lo em um estado completo que pode não ter existido nunca em um dado momento." (1865). VIOLLET-LE-DUC. Eugène E. Restauração. Cotia, Ateliê, 2000, p. 29.

(29) "Do not let us talk then of restoration. The thing is a Lie from beginning to end. You may make a model of a building as you may of a corpse, and your model may have the shell of the old walls within it as your cast might have the skeleton, with what advantage I neither see nor care: but the old building is destroyed.". RUSKIN, John. The Complete Works of John Ruskin. Londres: George Allen, 1903-1912, vol. 8, p. 242 (The Seven Lamps of Architecture, 1849).

(30) "A. Conclusões Gerais. I. Doutrinas. Princípios Gerais. A conferência assistiu à exposição dos princípios gerais e das doutrinas concernentes à proteção dos monumentos. Qualquer que seja a diversidade dos casos específicos - e cada caso pode comportar uma solução própria -, a conferência constatou que nos diversos Estados representados predomina uma tendência geral a abandonar as reconstituições integrais, evitando assim seus riscos, pela adoção de uma manutenção regular e permanente, apropriada para assegurar a conservação dos edifícios. Nos casos em que uma restauração pareça indispensável devido à deterioração ou destruição, a conferência recomenda que se respeite a obra histórica e artística do passado, sem prejudicar o estilo de nenhuma época. A conferência recomenda que se mantenha uma utilização dos monumentos que assegure a continuidade de sua vida, destinando-os sempre a finalidades que respeitem o seu caráter histórico ou artístico." Carta de Atenas, consultada no portal do IPHAN. http://portal.iphan.gov.br/portal/baixaFcdAnexo.do?id=232

(31) Cf. MAZZOCCA, F. Roma 1804-1808: Canova e la Venere Vincitrice. In: CANOVA e la Venere vincitrice. Milão: Electa, 2007, p. 19-44.

(32) BRANDI, Cesare. Teoria da Restauração. Cotia: Ateliê, 2004, p. 131.

\section{Referências bibliográficas}

AUGÉ, M. Le temps en ruines. Paris: Galilé, 2003.

AUGÉ, M. Rovine e macerie. I/ senso del tempo. Torino: Bollati Boringhieri, 2004.

BRANDI, Cesare. I/ restauro. Teoria e pratica [organização M. Cordaro]. Roma: Editori Riuniti, 1994.

BRANDI, Cesare. Teoria da restauração. Cotia: Ateliê, 2004.

CANOVA e la Venere vincitrice. Milão: Electa, 2007

DAEGENS, B. Angkor heart of an Asian Empire. New York: Abrams, 1995. 
PAINE, T. Being an Answer to Mr. Burke's Attack on the French Revolution. In: The rights of Man. Baltimore: J. Johnson, 1791. Tradução italiana: PAINE, T. I diritti dell'uomo e altri scritti politici [organização T. Magri]. Roma: Editori Riuniti, 1978.

PAVANELlO, G. (Org.) Antonio Canova: disegni e dipinti del Museo civico di Bassano del Grappa e della Gipsoteca di Possagno presentati all'Ermitage. Milão: Skira, 2001.

RUSKIN, John. The Complete Works of John Ruskin. Londres: George Allen, 1903-1912. p. 242. v. 8. (The Seven Lamps of Architecture, 1849).

SIMMEL, G. Die Ruine in Philosophische Kultur. Leipzig: Alfred Kröner Verlag, 1919.

SIMMEL, G. Saggi di cultura filosofica. Tradução italiana de M. Monadi: Milano: Longanesi, 1985.

VIOLLET-LE-DUC. Eugène E. Restauração. Cotia: Ateliê, 2000.

\section{Crédito}

* Arquiteto. Colabora, desde 2004, em diversos cursos voltados ao restauro na Faculdade de Arquitetura Valle Giulia da Università degli Studi di Roma "La Sapienza".

Tradução: Beatriz Mugayar Kühl - Arquiteta. Livre Docente pela FAU-USP. Docente do Departamento de História da Arquitetura e Estética do Projeto da FAU-USP. 